\title{
Assessment of Quality of Life in Bronchial Asthma Patients
}

\author{
Rashid Ali ${ }^{1}$, Naseem Ahmed ${ }^{1}$, Muhammad Salman ${ }^{2}$, Sofia Daudpota ${ }^{3}$, Madiha Masroor ${ }^{4}$, Muhammad
} $\operatorname{Nasir}^{5}$

1. Chest Medicine, Jinnah Postgraduate Medical Centre, Karachi, PAK 2. Paediatrics and Child Health, The Aga Khan University, Karachi, PAK 3. Pulmonary Medicine, Jinnah Postgraduate Medical Centre, Karachi, PAK 4. Internal Medicine, Critical Care Unit, South City Hospital, Karachi, PAK 5. Critical Care Medicine, Anesthesiology, South City Hospital, Karachi, PAK

Corresponding author: Muhammad Nasir, drmuhammadnasirkhoso@gmail.com

\section{Abstract}

\section{Introduction}

Asthma, a well-known chronic respiratory disease, is common worldwide. This study aimed to assess the quality of life in bronchial asthma patients and to determine the factors leading to poor quality of life among these patients.

\section{Materials and methods}

A cross-sectional study was conducted at a public sector hospital. The sample size was calculated as 134, with a nonprobability consecutive sampling technique. The Ethical Review Committee approved the study protocol. Demographic and asthma quality of life data were collected via a questionnaire. Data were analyzed IBM SPSS Statistics for Windows, Version 19.0 (Armonk, NY: IBM Corp.). Multivariate logistic regression was performed to observed the effect of these variables on the poor quality of life. A regression coefficient and odds ratio with a confidence interval of $95 \%$ and P-value $\leqslant .05$ were taken as significant.

\section{Results}

The average age of patients was $40.6 \pm 9.5$ years. In this study, 96 of 134 patients $(71.4 \%)$ with bronchial asthma reported a poor quality of life. In the univariate analysis, advanced age ( $\geqslant 40$ years), obesity, being female, family history of asthma, pets at home, and moderate severity of asthma significantly contributed to poor quality of life. Multivariate logistic regression was performed, and it was observed that advanced age (» 40 years), being female, a pet at home, and moderate severity of asthma were four to 13 times more likely to predict a poor quality of life for patients with bronchial asthma.

\section{Conclusions}

Review began 09/17/2020 Review ended 10/04/2020 Published 10/08/2020

\section{(c) Copyright 2020}

Ali et al. This is an open access article distributed under the terms of the Creative Commons Attribution License CC-BY 4.0., which permits unrestricted use, distribution, and reproduction in any medium, provided the original author and source are credited.
The severity of asthma significantly contributed to poor quality of life. Health facilitators should look into the causes of such risk to increase the perception of health-related quality of life (HRQoL) among asthma patients.

Categories: Internal Medicine, Pulmonology, Quality Improvement

Keywords: asthma, bronchial asthma, copd, hrqol

\section{Introduction}

Asthma, a well-known chronic respiratory disease, is one of the most common global problems, with an estimated total of 300 million affected individuals, comprising all age groups and exerting a significant burden on patients and their families [1]. The asthma load report by the Global Initiative for Asthma indicates that the prevalence of asthma ranges from $1 \%$ to $18 \%$ of the population $[1,2]$. Patients diagnosed with chronic obstructive pulmonary disease (COPD) have significantly reduced health-related quality of life (HRQoL) and account for 250,000 deaths per year worldwide [3]. HRQoL is a vital factor in pulmonary illnesses [4], and COPD can reduce HRQoL via physical and psychosocial complications [5].

Though asthma negatively impacts the quality of life of the patients, the core influencing factors are not fully understood. The most severe forms of asthma are integrated with a poor HRQoL with nonlinear coordination [6,7]. Factors need to be identified to improve HRQoL [6-8]. Motaghi-Nejad et al. found that asthma has a negative influence on the HRQoL in $48.3 \%$ of patients [9]. Gonzalez-Barcala et al. analyzed factors associated with a poor HRQoL like obesity (24.9\%), being female (28\%), advanced age (21.7\%), low education (56.5\%), family history of asthma (24.4\%), moderate persistent severity of asthma (36.4\%), being a smoker (23.3\%), and pets at home (24.4\%) [10]. HRQoL interventions are integrated with several clinical trials [11-13]. Furthermore, no local study data on effective pharmacotherapy are available. The study aims 
to assess the relationship between asthma severity and HRQoL and determine the primary factors in asthma that impact patient quality of life.

\section{Materials And Methods}

This cross-sectional study was held at the outpatient department of a public sector hospital. The sample size $(\mathrm{N}=134)$ was estimated on the prevalence rate of factors (12.7\%) through the help of the World Health Organization sample size calculator [12]. A confidence interval (CI) of $95 \%$ and a non-probability consecutive sampling technique was used during data collection. All patients with mild to moderate persistent asthma were classified according to the tool defined by the Guidelines for the Diagnosis and Management of Asthma [13]. Patients ranged from 18 to 60 years in age and were of either sex. Patients had clinical stability, no exacerbation, and had asthma for at least six months and treatment for the prior two weeks. Patients unwilling to participate were excluded from the study along with patients with acute severe/persistent asthma and those with a history of severe respiratory tract infection/chronic rhinosinusitis, pulmonary tuberculosis, or lung cancer the past month. Ethical approval was granted from the Institutional Ethical Review Committee.

All subjects fulfilling the eligibility criteria were enrolled after providing informed verbal and written consent. The principal investigator interviewed the patients in the outpatient department of a public hospital. Each interview lasted 10 to 20 minutes. Data were collected on a proforma and included basic demographic information such as age, sex, body mass index (BMI), duration of disease, duration of treatment, place of residency, occupation, education, and economic status, addiction, smoking status, the severity of asthma, and pet exposure. A predesigned Asthma Quality of Life Questionnaire (AQLQ) was used with permission [11-16]. This scale, developed in Canada, assesses the quality of life of asthmatic patients and includes physical and emotional health, subjective health status, and domains of functioning that are important to patients. The data were entered and analyzed by using IBM SPSS Statistics for Windows, Version 19.0 (Armonk, NY: IBM Corp.). The mean and standard deviation was calculated for age, BMI, duration of asthma, duration of treatment, and AQLQ score. The frequency and percentage were calculated for sex, the severity of asthma, residency, quality of life (poor/satisfactory), and other factors (BMI, age, sex, education, economic status, smoking habits, pets at home, and asthma severity). Effect modifiers like age, sex, residency, duration of disease, duration of treatment, and the severity of asthma were controlled through multivariate analysis instead of stratification techniques. Multivariate logistic regression was performed to observe the effect of these variables on the quality of life. The regression coefficient and odds ratio, with a $95 \% \mathrm{CI}$, were reported. A P-value $\leqslant .05$ was considered significant.

\section{Results}

A total of 134 diagnosed cases of asthma for at least six months and on treatment for at least two weeks were selected in this study. The average age of the patients was $40.6 \pm 9.5$ years ( $95 \%$ CI: 39.04 to 42.29 ). Average BMI, duration of asthma, duration of treatment, AQLQ score is presented in Table 1 . There were 79 (58.96\%) men and 55 (41.04\%) women. Intermittent asthma was found in $12.69 \%$ of patients, mild asthma in $29.85 \%$, and moderate asthma in $57.46 \%$ (Figure 1 ).

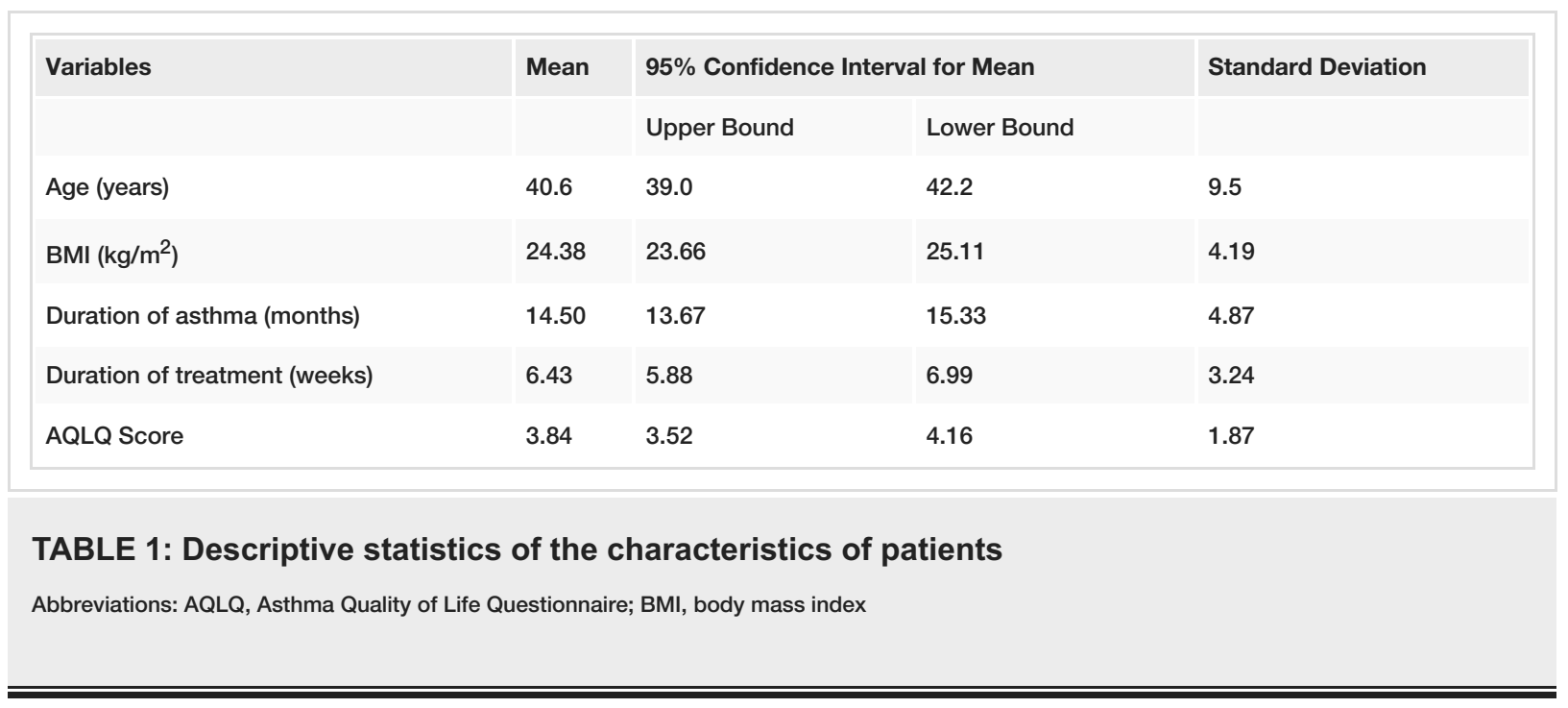




\section{Cureus}

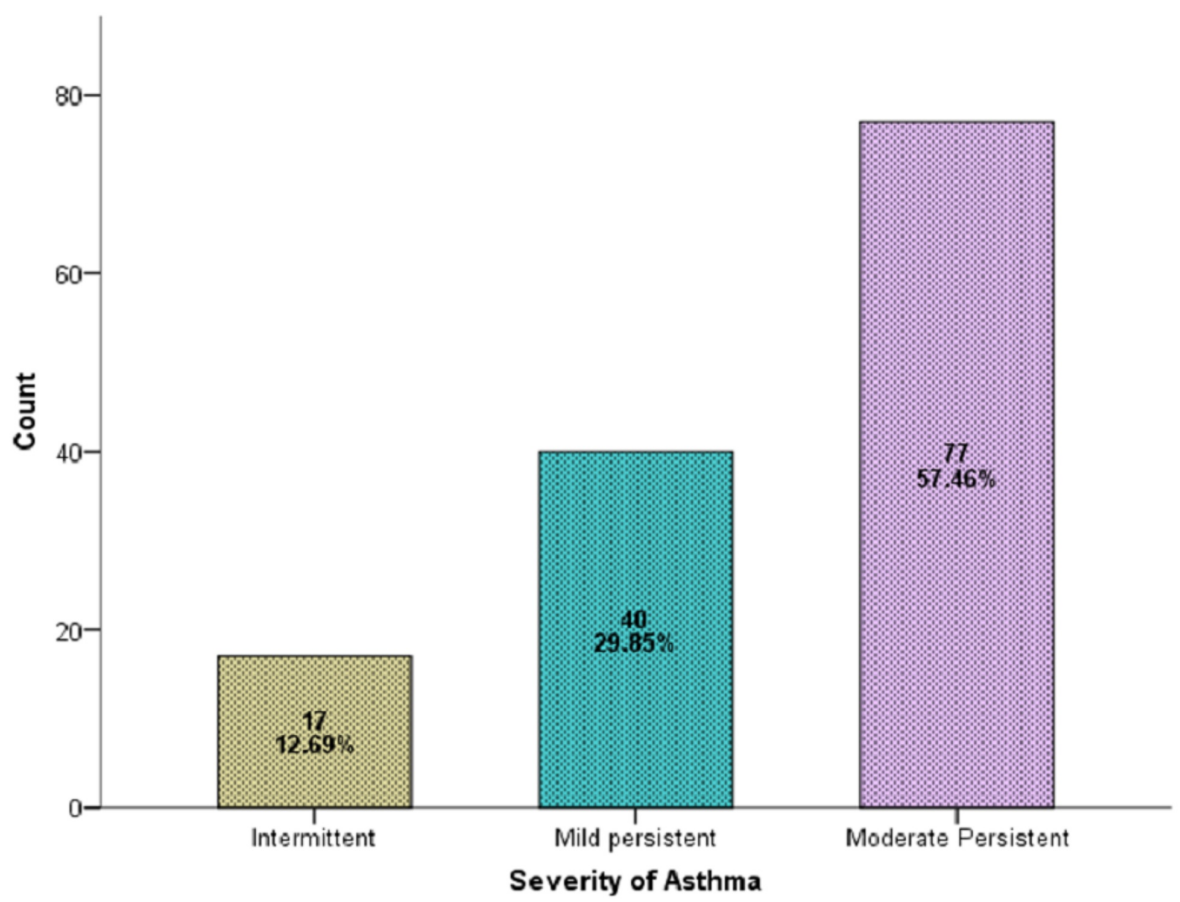

FIGURE 1: Severity of asthma $(n=134)$

Ninety-six of 134 (71.4\%) patients were observed with a poor quality of life in bronchial asthma (Figure 2). Table 2 presents factors contributing to poor quality of life in bronchial asthma patients. An age of 40 years or older, obesity, being female, pets at home, and moderate severity of asthma significantly contributed to poor quality of life while low educational status, family history of asthma, and smoking habits did not have a significant impact. Multivariate logistic regression revealed that advanced age ( $\geqslant 40$ years), being female, a pet at home, and moderate severity of asthma were four to 13 times more likely to predict a poor quality of life in bronchial asthma (Table 3). The model specification of the logistic regression is also presented in Table 3. 


\section{Cureus}

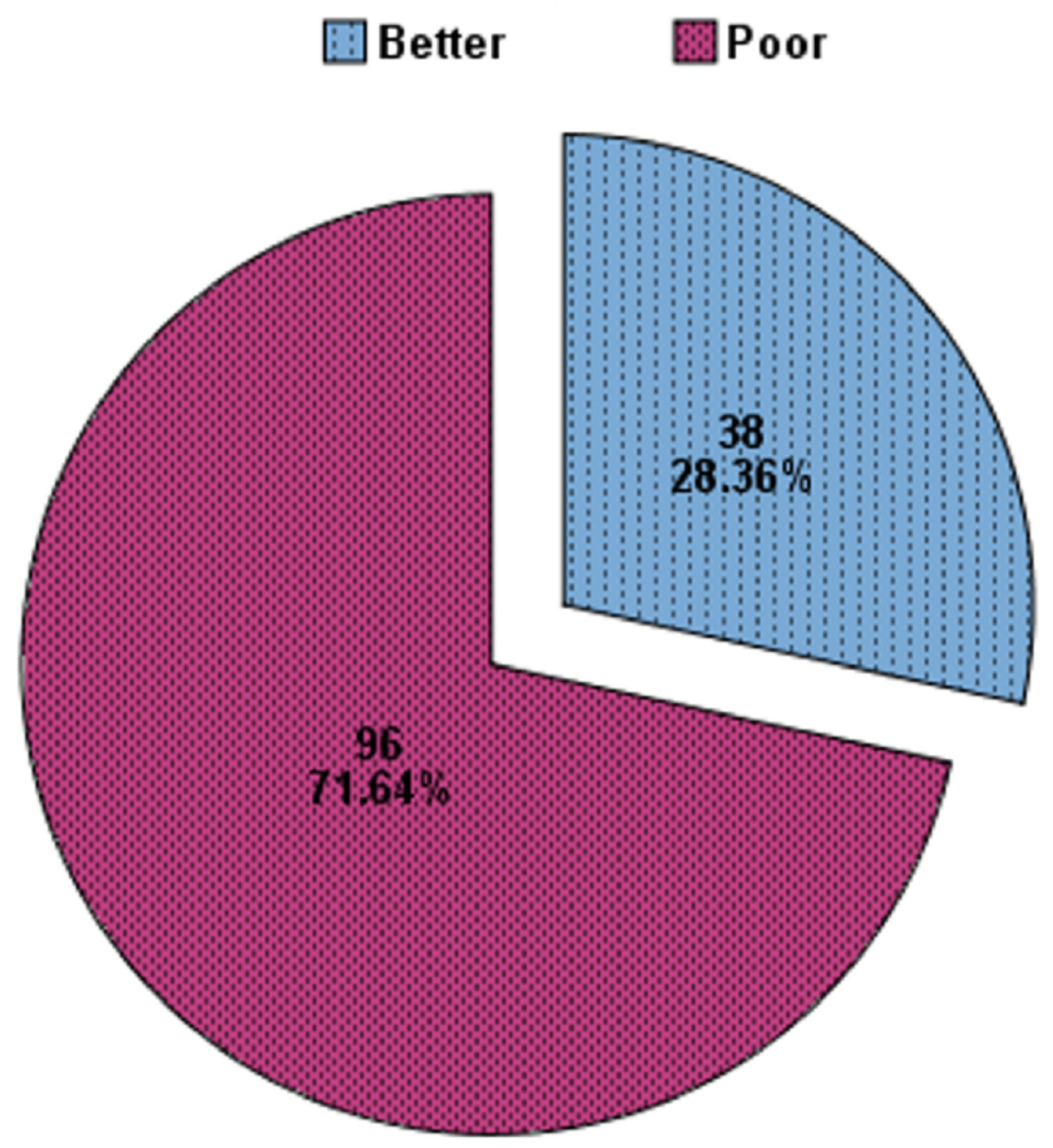

FIGURE 2: Quality of life in bronchial asthma patients $(n=134)$ 


\section{Cureus}

\begin{tabular}{|c|c|c|c|c|}
\hline \multirow[t]{2}{*}{ Factors } & \multirow[t]{2}{*}{$\mathbf{N}$} & \multicolumn{2}{|c|}{ Quality of life } & \multirow[t]{2}{*}{ P-value } \\
\hline & & Poor & Better & \\
\hline \multicolumn{5}{|l|}{ Advanced age } \\
\hline$\geq 40$ Years & 73 & $61(83.6 \%)$ & $12(16.4 \%)$ & .001 \\
\hline$<40$ Years & 61 & $35(57.4 \%)$ & $26(42.6 \%)$ & \\
\hline \multicolumn{5}{|l|}{ Obesity } \\
\hline $\mathrm{BMI} \geq 25 \mathrm{~kg} / \mathrm{m}^{2}$ & 52 & 47 (90.4\%) & $5(9.6 \%)$ & .0005 \\
\hline $\mathrm{BMI}<25 \mathrm{~kg} / \mathrm{m}^{2}$ & 82 & $49(59.8 \%)$ & $33(40.2 \%)$ & \\
\hline \multicolumn{5}{|l|}{ Gender } \\
\hline Men & 79 & $48(60.8 \%)$ & 31 (39.2\%) & .001 \\
\hline Women & 55 & $48(87.3 \%)$ & $7(12.7 \%)$ & \\
\hline \multicolumn{5}{|l|}{ Education Level } \\
\hline Uneducated & 88 & $67(76.1 \%)$ & $21(23.9 \%)$ & .100 \\
\hline Educated & 46 & $29(63 \%)$ & $17(37 \%)$ & \\
\hline \multicolumn{5}{|l|}{ Socioeconomic Status } \\
\hline Low & 56 & $43(76.8 \%)$ & $13(23.2 \%)$ & .383 \\
\hline Middle & 74 & $51(68.9 \%)$ & $23(31.1 \%)$ & \\
\hline High & 4 & $2(50 \%)$ & $2(50 \%)$ & \\
\hline \multicolumn{5}{|c|}{ Family History of Asthma } \\
\hline Yes & 66 & $53(80.3 \%)$ & $13(19.7 \%)$ & .028 \\
\hline No & 68 & $43(63.2 \%)$ & $25(36.8 \%)$ & \\
\hline \multicolumn{5}{|l|}{ Smoker } \\
\hline Yes & 59 & $46(78 \%)$ & $13(22 \%)$ & .150 \\
\hline No & 75 & $50(66.7 \%)$ & $25(33.3 \%)$ & \\
\hline \multicolumn{5}{|l|}{ Pets at home } \\
\hline Yes & 42 & 39 (92.9\%) & $3(7.1 \%)$ & .0005 \\
\hline No & 92 & 57 (62\%) & $35(38 \%)$ & \\
\hline \multicolumn{5}{|l|}{ Severity of Asthma } \\
\hline Moderate & 77 & $25(43.9 \%)$ & 32 (56.1\%) & .0005 \\
\hline Mild and intermitted & 57 & 71 (92.2\%) & $6(7.8 \%)$ & \\
\hline
\end{tabular}

TABLE 2: Factors leading to poor quality of life in bronchial asthma patients Abbreviation: BMI, body mass index 


\section{Cureus}

\begin{tabular}{|c|c|c|c|c|c|c|}
\hline \multirow{2}{*}{ Variables } & \multirow{2}{*}{ Regression Coefficient } & \multirow{2}{*}{ SE } & \multirow{2}{*}{ P-value } & \multirow{2}{*}{ OR } & \multicolumn{2}{|c|}{$95 \% \mathrm{Cl}$ for OR } \\
\hline & & & & & Lower & Upper \\
\hline Advance Age ( $\geq 40$ Years) & 1.387 & .592 & .019 & 4.00 & 1.25 & 12.76 \\
\hline Obesity (BMI $\geq 25 \mathrm{~kg} / \mathrm{m}^{2}$ ) & .844 & .671 & .208 & 2.32 & 0.62 & 8.65 \\
\hline Female Gender & 1.732 & .727 & .017 & 5.65 & 1.36 & 23.50 \\
\hline Uneducated Patients & .617 & .666 & .354 & 1.85 & 0.50 & 6.84 \\
\hline Low Socioeconomic status & .638 & .683 & .350 & 1.89 & 0.49 & 7.21 \\
\hline Family History of Asthma (Yes) & .862 & .575 & .134 & 2.36 & 0.76 & 7.30 \\
\hline Smoker (Yes) & 1.112 & .688 & .106 & 3.04 & 0.79 & 11.71 \\
\hline Pet At Home(Yes) & 1.806 & .821 & .028 & 6.08 & 1.21 & 30.45 \\
\hline Residency (Rural) & .268 & .601 & .656 & 1.30 & 0.40 & 4.24 \\
\hline Duration of Asthma (Months) & .087 & .080 & .278 & 1.09 & 0.93 & 1.27 \\
\hline Duration of Treatment of Asthma (weeks) & -.046 & .097 & .636 & 0.95 & 0.78 & 1.15 \\
\hline Severity of Asthma (Moderate) & 2.617 & .672 & .0005 & 13.68 & 3.66 & 51.12 \\
\hline Constant & -4.669 & 1.810 & .010 & .009 & & \\
\hline
\end{tabular}

TABLE 3: Multivariate logistic regression model to predict a poor quality of life in bronchial asthma

Abbreviations: $\mathrm{BMI}$, body mass index; $\mathrm{Cl}$, confidence interval; OR, odds ratio; SE, standard error.

Dependent variable $=$ Quality of Life (Poor, Better)

Model Summary: Model Accuracy = 90.3\%; -2 Log likelihood = 83.14; Cox \& Snell R Square = 43.6\%; Nagelkerke R Square= 62.5\%

\section{Discussion}

Our patient population age and male-to-female ratio were similar to the demographics of similar studies reported by Gonzalez-Barcala [10] and Nalina and Chandra [17].

Most of our patients (71.4\%) reported a poor quality of life with bronchial asthma, which was higher than the percentage of those reporting a poor quality of life in the report by Motaghi-Nejad et al., who found that only $48.3 \%$ of patients reported a poor quality of life [9]. The reasons for the higher incidence of poor quality of life in our patients were likely due to our study population's more advanced age (> 40 years) and lower educational and socioeconomic status than those in Motaghi-Nejad et al.'s patient population.

In the present study, advanced age $\geqslant 40$ years, obesity, being female, family history of asthma, pets at home, and moderate severity of asthma was significantly contributors to poor quality of life. Gonzalez-Barcala et al. reported similar findings but also found that a low education level (56.5\%) and smoking status (23.3\%) were associated with a poor HRQoL. These findings were consistent with our results [10]. However, unlike Gonzalez-Barcala et al., we did not address the impact of recurrent admissions on the HRQoL [10].

Even though no association was seen among age and HRQoL [18,19], several authors have noticed a decrease in HRQoL with increasing age [20,21]. Many factors are associated with age and illness, including immunosenescence [22-24]. As comorbidities increase with age, they contribute to the symptomatology and even prohibit the use of certain asthma medications due to contraindications $[22,23]$.

Lower health proficiency has been reported in patients with a lower education level. Likewise, lower numerical aptitudes, progressively postponed determination of asthma, more unfortunate access to social status, or poorer health status could add to the decrease in HRQoL seen in these patients $[25,26]$.

Our study was limited in that the research reflects patients from a single hospital, which means our findings may not be generalizable across a wider geographic population. It is, therefore, recommended that similar studies be conducted in other locations across Pakistan to gain a more accurate assessment of a broad 
population.

\section{Conclusions}

This study identified several factors responsible for the poor quality of life of patients with asthma. These factors consisted of advanced age, increased asthma severity, poor control of asthma, low education level, and low socioeconomic status. Given the relevant impact of economic and education levels, it is essential that health care providers ensure that patients receive proper education for the prevention of asthma symptoms and provide supportive care when possible to help patients achieve a good quality of life.

\section{Additional Information}

\section{Disclosures}

Human subjects: Consent was obtained by all participants in this study. Institutional Review Board Committee JPMC, Karachi issued approval NO.F.2-81/2017-GENL/8822/JPMC. Institutional Review Board has approved. Animal subjects: All authors have confirmed that this study did not involve animal subjects or tissue. Conflicts of interest: In compliance with the ICMJE uniform disclosure form, all authors declare the following: Payment/services info: All authors have declared that no financial support was received from any organization for the submitted work. Financial relationships: All authors have declared that they have no financial relationships at present or within the previous three years with any organizations that might have an interest in the submitted work. Other relationships: All authors have declared that there are no other relationships or activities that could appear to have influenced the submitted work.

\section{References}

1. Masoli M, Fabian D, Holt S, Beasley R: The global burden of asthma: executive summary of the GINA Dissemination Committee Report. Allergy. 2004, 59:469-478. 10.1111/j.1398-9995.2004.00526.x

2. Bjornson CL, Russell K, Plint A, Rowe BH: The Cochrane Library and leukotriene receptor antagonists for children with asthma: an overview of reviews. Evidence-Based Child Health A Cochrane Rev J. 2008, 3:595602. 10.1002/ebch.245

3. Voll-Aanerud M, Eagan TM, Plana E, et al.: Respiratory symptoms in adults are related to impaired quality of life, regardless of asthma and COPD: results from the European community respiratory health survey. Health Qual Life Outcomes. 2010, 8:107. 10.1186/1477-7525-8-107

4. Ismaila AS, Sayani AP, Marin M, Su Z: Clinical, economic, and humanistic burden of asthma in Canada: a systematic review. BMC Pulm Med. 2013, 13:70. 10.1186/1471-2466-13-70

5. Mancuso CA, Choi TN, Westermann H, Wenderoth S, Wells MT, Charlson ME: Improvement in asthma quality of life in patients enrolled in a prospective study to increase lifestyle physical activity. J Asthma. 2013, 50:103-107. 10.3109/02770903.2012.743150

6. Siroux V, Boudier A, Bousquet J, et al.: Asthma control assessed in the EGEA epidemiological survey and health-related quality of life. Respir Med. 2012, 106:820-828. 10.1016/j.rmed.2012.01.009

7. Cui W, Zack MM, Zahran HS: Health-related quality of life and asthma among United States adolescents . I Pediatr. 2015, 166:358-364. 10.1016/j.jpeds.2014.10.005

8. Janssen MF, Pickard AS, Golicki D, et al.: Measurement properties of the EQ-5D-5L compared to the EQ-5D3L across eight patient groups: a multi-country study. Qual Life Res. 2013, 22:1717-1727. 10.1007/s11136012-0322-4

9. Motaghi-Nejad M, Shakerinejad G, Cheraghi M, Tavakkol H, Saki A: Quality of life in asthmatic patients. Int J Bioassays. 2015, 4:3757-3762. 10.1.1.1008.2477

10. Gonzalez-Barcala F-J, de la Fuente-Cid R, Tafalla M, Nuevo J, Caamaño-Isorna F: Factors associated with health-related quality of life in adults with asthma. A cross-sectional study. Multidiscip Respir Med. 2012, 7:32. 10.1186/2049-6958-7-32

11. Pont LG, van der Molen T, Denig P, van der Werf GT, Haaijer-Ruskamp FM: Relationship between guideline treatment and health-related quality of life in asthma. Eur Respir J. 2004, 23:718-722. 10.1183/09031936.04.00065204

12. Juniper EF, Buist AS, Cox FM, Ferrie PJ, King DR: Validation of a standardized version of the asthma quality of life questionnaire. Chest. 1999, 115:1265-1270. 10.1378/chest.115.5.1265

13. National Asthma Education and Prevention Program - third expert panel on the diagnosis and management of asthma: expert panel report 3: Guidelines for the Diagnosis and Management of Asthma. (2007). Accessed). Accessed: August 26, 2020: https://www.ncbi.nlm.nih.gov/books/NBK7232/.

14. Mahapatra P, Murthy K, Kasinath P, Yadagiri R: Social, Economic \& Cultural Aspects of Asthma: an Exploratory Study in Andhra Pradesh, India. Institute of Health Systems, India 1993.

15. Juniper EF: Using humanistic health outcomes data in asthma. Pharmacoeconomics. 2001, 19:13-19. 10.2165/00019053-200119002-00003

16. Juniper EF, Guyatt GH, Epstein RS, Ferrie PJ, Jaeschke R, Hiller TK: Evaluation of impairment of health related quality of life in asthma: development of a questionnaire for use in clinical trials. Thorax. 1992, 47:76-83. 10.1136/thx.47.2.76

17. Nalina N, Chandra M: Umashankar: assessment of quality of life in bronchial asthma patients . Int J Med Public Heal. 2015, 5:93-97. 10.4103/2230-8598.151270

18. Apter AJ, Reisine ST, Affleck G, Barrows E, ZuWallack RL: The influence of demographic and socioeconomic factors on health-related quality of life in asthma. J Allergy Clin Immunol. 1999, 103:72-78. 10.1016/S00916749(99)70528-2

19. Erickson S, Christian R, Kirking D, Halman L: Relationship between patient and disease characteristics, and health-related quality of life in adults with asthma. Respir Med. 2002, 96:450-460. 10.1053/rmed.2001.1274 


\section{Cureus}

20. Plaza V, Serra-Batlles J, Ferrer M, Morejón E: Quality of life and economic features in elderly asthmatics . Respiration. 2000, 67:65-70. 10.1159/000029465

21. Siroux V, Boudier A, Anto JM, et al.: Quality-of-life and asthma-severity in general population asthmatics: results of the ECRHS II study. Allergy. 2008, 63:547-554. 10.1111/j.1398-9995.2008.01638.x

22. Gibson PG, McDonald VM, Marks GB: Asthma in older adults. Lancet. 2010, 376:803-813. 10.1016/S01406736(10)61087-2

23. Busse PJ, Mathur SK: Age-related changes in immune function: effect on airway inflammation . J Allergy Clin Immunol. 2010, 126:690-699. 10.1016/j.jaci.2010.08.011

24. Bellia V, Scichilone N, Battaglia S: Asthma in the elderly. Eur Respir Mon. 2009, 43:56-76.

25. Mancuso CA, Rincon M: Impact of health literacy on longitudinal asthma outcomes . J Gen Intern Med. 2006, 21:813-817. 10.1111/j.1525-1497.2006.00528.x

26. Santos MS, Jung H, Peyrovi J, Lou W, Liss GM, Tarlo SM: Occupational asthma and work-exacerbated asthma. Chest. 2007, 131:1768-1775. 10.1378/chest.06-2487 